\title{
Communication
}

\section{Wax Extracted from Waste Cauliflower Leaves Shows Potential Antitranspirant Efficacy When Applied to Rapeseed Plants}

\author{
Michele Faralli ${ }^{1, *, \dagger}$, Minuka Weerasinghe ${ }^{1}$, Gee-Sian Leung ${ }^{2}$, Ray Marriott ${ }^{2, \ddagger}$, Melville Miles ${ }^{3, \S}$ \\ and Peter Kettlewell ${ }^{1, *(D)}$
}

1 Drought Mitigation Group, Agriculture and Environment Department, Harper Adams University, Newport, Shropshire TF10 8NB, UK; minuweera@yahoo.com

2 Suprex Limited, Unit 10, Zone 6, Cibyn Industrial Estate, Caernarfon, Gwynedd LL55 2BD, UK; g.leung@bangor.ac.uk (G.-S.L.); r.marriott@bangor.ac.uk (R.M.)

3 Freshtime Limited, The Found Riverside Industrial Estate, Marsh Lane, Boston PE21 7PJ, UK; Melville.Miles@greencore.com

* Correspondence: michele.faralli@unitn.it (M.F.); pskettlewell@harper-adams.ac.uk (P.K.)

+ Present addresses: Center Agriculture Food Environment (C3A), University of Trento, 38098 San Michele all'Adige, Italy.

‡ Present addresses: BioComposites Centre, Bangor University, Bangor, Gwynedd LL57 2UW, UK.

$\S$ Present addresses: Greencore, UK Centre, Midland Way, Barlborough, Chesterfield S43 4XA, UK.

Citation: Faralli, M.; Weerasinghe, M.; Leung, G.-S.; Marriott, R.; Miles, M.; Kettlewell, P. Wax Extracted from Waste Cauliflower Leaves Shows Potential Antitranspirant Efficacy When Applied to Rapeseed Plants. Agronomy 2022, 12, 455. https:// doi.org/10.3390/agronomy12020455

Academic Editor: Yoshiharu Fujii

Received: 15 January 2022

Accepted: 10 February 2022

Published: 11 February 2022

Publisher's Note: MDPI stays neutral with regard to jurisdictional claims in published maps and institutional affiliations.

Copyright: (C) 2022 by the authors. Licensee MDPI, Basel, Switzerland. This article is an open access article distributed under the terms and conditions of the Creative Commons Attribution (CC BY) license (https:// creativecommons.org/licenses/by/ $4.0 /)$.

\begin{abstract}
The stress from excessive transpiration of water from plant leaves can damage crop growth during droughts. Specific commercial biostimulant products (antitranspirants) are available to reduce transpiration when applied to plants, but these products are expensive. Antitranspirants from waste would be cheaper, and the aim of this research was to extract leaf wax from a fresh produce processing waste and conduct a preliminary evaluation of its antitranspirant efficacy. Supercritical $\mathrm{CO}_{2}$ was used to extract wax from cauliflower leaves, and after formulating for spraying, the wax was applied to young rapeseed plants in three consecutive experiments. The wax was compared with a commercially-available terpene antitranspirant (di-1-p-menthene) for efficacy in reducing stomatal conductance and water use. In two of the three experiments, stomatal conductance was significantly reduced to similar extents by wax and by di-1- $p$-menthene, despite the wax being formulated and applied at a much lower concentration. Water use was reduced by wax in one experiment. Further research is needed on formulation, spraying conditions, and dose-response. These preliminary results demonstrate the potential for extracted leaf wax to act as a biostimulant and ameliorate plant drought stress.
\end{abstract}

Keywords: nonacosane; epicuticular wax; oilseed rape; canola

\section{Introduction}

Water shortages throughout the world, exacerbated by climate change, are accelerating the adoption of technologies to help crop production use less water [1,2]. One little-used technology is the retardation of water vapour loss from stomata on the leaves of crop plants by the application of polymers, referred to as film antitranspirants in this context. These polymers are used on high-value ornamental plants, but are not yet widely-used on lower-value major food crops [3].

Recent research has revealed the potential for these polymers to reduce food crop yield loss from drought if application is timed to drought-sensitive stages of development in wheat [4,5] and in rapeseed [6]. Appropriately-timed film antitranspirant applications under drought have been previously associated with enhanced water saving strategies, lowered abscisic acid accumulation and an increase in leaf intrinsic water use efficiency leading to sustained key yield components under distinct reduced water availability patterns [4-6]. A further use of film antitranspirants is to reduce photosynthesis and, thus, excessive sugar 
accumulation in grapes resulting from rising temperature as the climate changes $[7,8]$. However, the problem with current commercially-available film antitranspirant products is that they are expensive, and this inhibits their use in crop production. A cheaper film antitranspirant would facilitate their use in crop production. One possibility for producing a cheaper product may be to use waste material as a source of antitranspirant, and in our study we use waste leaves trimmed from brassica produce after harvesting. Currently, fresh produce processors in the UK send waste brassica leaves for either anaerobic digestion or livestock feed. Brassica species have a substantial layer of leaf wax, e.g., [9], which in all plants has evolved as a natural barrier covering the majority of the leaf surface to reduce water vapour loss from the leaf cuticle [10]. If this wax could be extracted cheaply, it may act as an antitranspirant if appropriately formulated and sprayed onto plants at risk of water stress. Thus, the hypothesis tested in our study was that leaf wax extracted from cauliflower trimming waste may have the potential to reduce transpiration when applied to rapeseed plants.

The objectives of the studies described in this paper were:

1. To extract wax using supercritical $\mathrm{CO}_{2}$ from cauliflower (Brassica oleracea L.) leaf waste and to formulate the wax for spraying as a film antitranspirant.

2. To evaluate the efficacy of this wax formulation in comparison with a current commercial film antitranspirant (di-1- $p$-menthene) for reducing stomatal conductance and water use of young glasshouse-grown plants of rapeseed (Brassica napus L.) in three experiments.

3. To compare the cost of the extracted wax with the cost of di-1-p-menthene.

\section{Materials and Methods}

An outline of the main steps in the research methodology is shown in Figure 1.

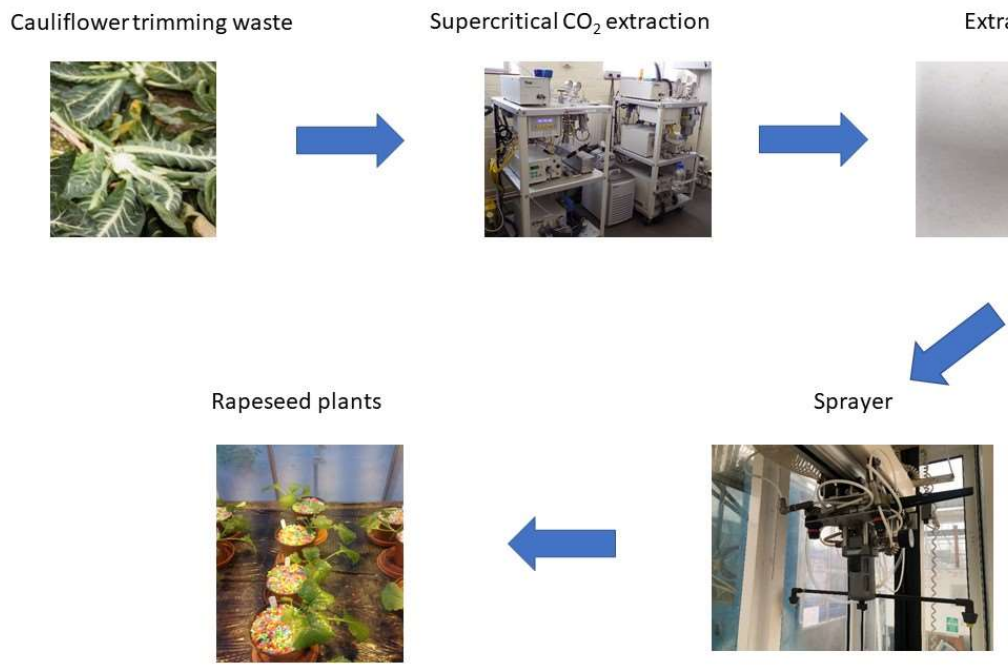

Figure 1. Main steps in the research methodology.

\subsection{Supercritical $\mathrm{CO}_{2}$ Extraction of Wax and Its Characterization}

Air-dried cauliflower leaves were extracted using a Thar SFC-1000 laboratory system fitted with a $2000 \mathrm{~mL}$ extractor and a $500 \mathrm{~mL}$ separator operating at $350 \mathrm{bar}, 50{ }^{\circ} \mathrm{C}$, $40 \mathrm{~g} \mathrm{minute}^{-1} \mathrm{CO}_{2}$ for $4 \mathrm{~h}$. The leaf wax deposited in the separator was recovered using dichloromethane and the dichloromethane was subsequently removed in vacuo. The yield of the leaf wax was measured and the wax compounds were analysed with an Agilent 6890 gas chromatograph coupled to an Agilent 5973 mass spectrometer (EI detector).

A $6 \%(\mathrm{~m} / \mathrm{m})$ cauliflower leaf wax formulation was prepared for in vivo plant assessments by adding wax and glycerol monostearate into hot water at a ratio of 1:2 along with $1.0 \%(\mathrm{~m} / \mathrm{m})$ of Tween 20 . This mixture was homogenised at $4000 \mathrm{rpm}$ using an IKA T18 basic Ultra-Turrax until an emulsion was formed. 


\subsection{Plant Material and Experimental Design}

Three seeds per pot were sown of rapeseed (cv. Excalibur) in $1 \mathrm{~L}$ pots $(13 \mathrm{~cm}$ top diameter) filled with $\sim 600 \mathrm{~g}$ of John Innes \#2 compost [11] at $22 \pm 1 \%$ volumetric water content (VWC) analysed with a soil moisture probe (ML2X theta probe, Delta-T Devices, Cambridge, UK). The pots were placed on a bench in a glasshouse at Harper Adams University $\left(52.8^{\circ} \mathrm{N} 2.4^{\circ} \mathrm{W}\right)$ and the pots were thinned to one plant at the 2 nd leaf stage. The solar radiation in the glasshouse was supplemented from sodium vapour lamps (Osram Ltd., Reading, UK, model: Vialox NAV-T 400) set to $16 \mathrm{hrs}$ per day. The glasshouse heating minimum temperature was set to $15^{\circ} \mathrm{C}$ during the day and $5{ }^{\circ} \mathrm{C}$ during the night, and because the experiments were conducted in winter, higher temperatures would have occurred only infrequently. The pots were manually watered approximately to saturation on the day that the seeds were sown and no water was applied until the seedlings appeared. After the seedlings appeared, until the application of the treatments, the pots were manually watered approximately to saturation every other day.

All three experiments had three spray treatments (water, di-1-p-menthene and wax) in six (Experiment 1) or eight (Experiments 2 and 3 ) randomised blocks.

\subsection{Water Management and Treatment Application}

The available water content (AWC) in $\mathrm{mL}$ of the pots was calculated by plotting a volumetric water content (VWC) - pot weight curve: three pots (filled with $\sim 600 \mathrm{~g}$ of compost at $22 \pm 1 \%$ VWC) were water-saturated and then dried over ten days at $30^{\circ} \mathrm{C}$. The VWC by soil moisture probe (ML2X theta probe 120, Delta-T Devices, Cambridge, UK) and the weight by balance (0.1 g resolution, PCB 2500-2, Kern and Sohn GmbH, Balingen, Germany) were recorded daily. For John Innes \#2 compost the permanent wilting point and the pot capacity were $\sim 7 \%$ VWC and $\sim 45 \%$ VWC, respectively [12]. The total AWC in $\mathrm{mL}$ was then calculated as the difference between the weight of the pot at pot capacity $(\sim 1000 \mathrm{~g})$ and the weight of the pot at $7 \%$ VWC $(\sim 650 \mathrm{~g})$ measured by moisture probe. Before the spray treatments were imposed, the surface of each pot was covered by $100 \mathrm{~g}$ of plastic beads, so that the water evaporation from the soil surface was minimised.

The spray treatments were applied 14 November 2016, 31 January 2017 and 20 February 2017 for the three experiments, respectively, at the 4th leaf stage. The 4 th leaf stage was chosen because by this stage the leaf area and water transpired should be large enough to enable measurement of water use by weight. Spraying occurred just after the pots were watered to pot capacity (45\% VWC) for the last time. After this date, the pots were not watered until the experiments ended at 10 days after spraying, which was also 10 days after the imposition of drought.

The three treatments were as follows: water (for control); $1 \% v / v$ Vapor Gard (di-1- $p$ menthene $96 \%$ [volumetric or gravimetric not stated], Miller Chemical and Fertilizer LLC, Hanover, USA) in water with no adjuvant; $1 \% v / v$ wax in water + adjuvant $0.5 \% v / v$ Wetcit (alcohol ethoxylate 9\%, ORO_AGRI Inc, Trophy Club, TX, USA). For Experiments 1 and 2, the adaxial surface of the leaves was uniformly sprayed using a $0.5 \mathrm{~L}$ hand-held trigger sprayer at a distance of a few $\mathrm{cm}$ until the surface was fully covered. This technique was chosen to ensure complete coverage of the adaxial leaf surface. The assessment of coverage of each plant during spraying is, however, subjective and, therefore, to reduce variation between plants in the quantity of spray applied in Experiment 3, the plants were sprayed using a custom-built automatic pot sprayer in an enclosed chamber that simulates a field crop sprayer more-closely (Figure 1). The twin nozzle spray boom had nozzles at $50 \mathrm{~cm}$ height from the plants, and delivered the spray at 3 bar pressure at $1 \mathrm{~m} / \mathrm{s}$ speed using Flat Fan 015 nozzles (Teejet, Rockford, MI, USA) delivering the equivalent of $200 \mathrm{~L} / \mathrm{ha}$.

\subsection{Physiological Assessments}

Stomatal conductance $\left(g_{s}\right)$ was measured on several days after spraying with a transient state diffusion porometer (AP4, Delta-T Devices, Cambridge, UK) calibrated before every use. Three readings for adaxial $g_{s}$ and abaxial $g_{s}$ were taken from the 3rd leaf of each 
plant, and the mean calculated. Data were collected between 11.00 am to $2.00 \mathrm{pm}$, in a blockwise manner to minimise any diurnal effect on $g_{s}$.

Plant water use was quantified every day from the date of the spray application to 10 days after spraying by weighing each pot between 8.30 am to $9.30 \mathrm{am}$. It was assumed that the beads completely blocked evaporation of water from soil. Daily water use of each pot was calculated as the difference between the weight of the pot on the day and the weight of the pot after $24 \mathrm{~h}$. Cumulative water use of each plant for the period of experimentation was calculated by summing up daily water use.

\subsection{Statistical Analysis}

All the data were analysed using Genstat (18th and 20th Editions, VSNi, Hemel Hempstead, UK). Adaxial and abaxial $g_{s}$ were analysed with a two factor (Time $\times$ Treatment) randomised complete block repeated measures ANOVA. Cumulative water use was analysed by a single factor (Treatment) randomised complete block ANOVA.

\section{Results}

The principal components of the wax were nonacosane, 15-nonacosanone, triacontane and $\gamma$-sitosterol (Figure 2), and we obtained a wax yield from dried leaves of $1.31 \%(\mathrm{~m} / \mathrm{m})$.

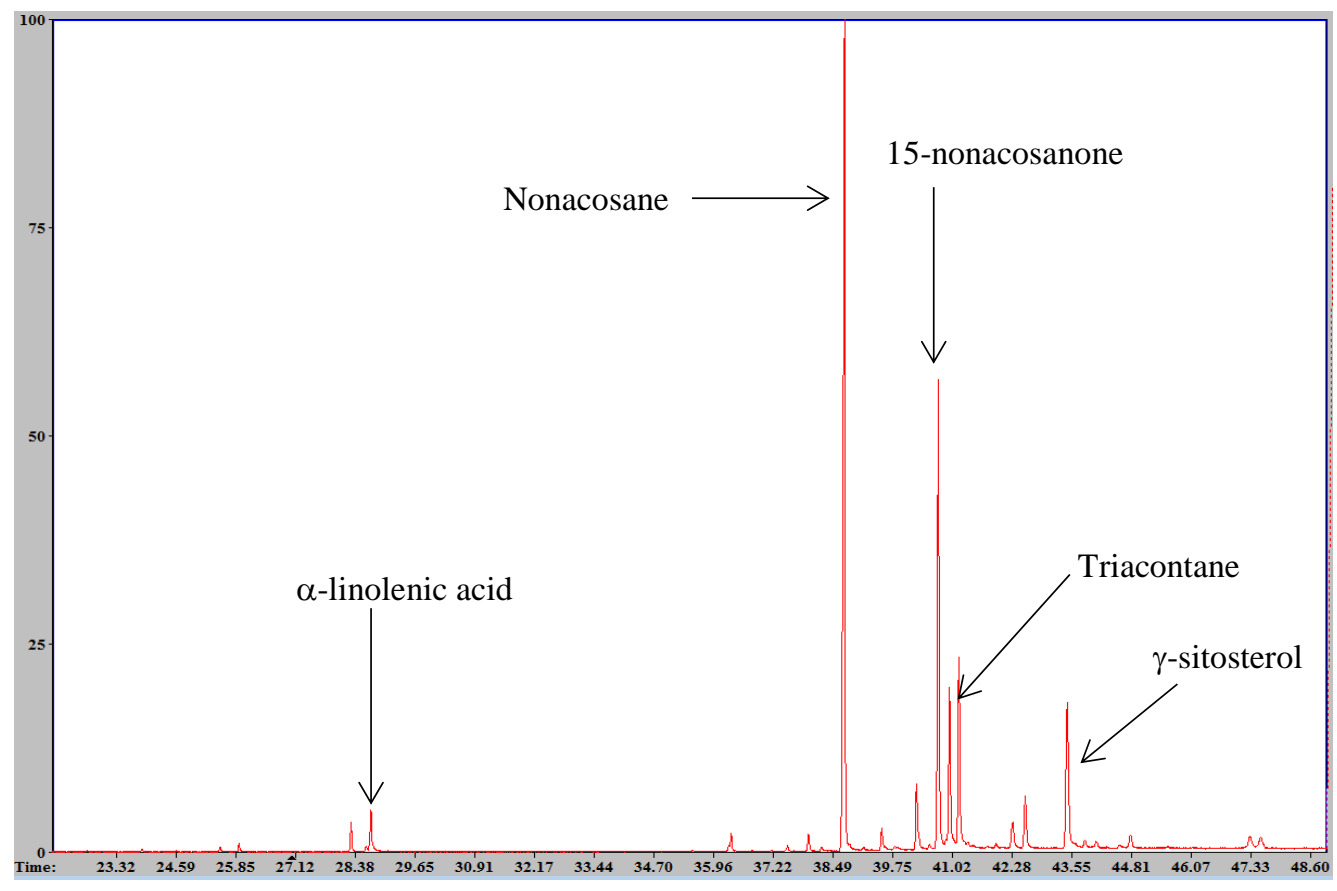

Figure 2. GC-MS chromatogram of soluble wax compounds in cauliflower leaves extracted using supercritical $\mathrm{CO}_{2}$.

Figure 3 shows that abaxial $g_{s}$ was higher than adaxial $g_{s}$ at the start of all three experiments and the $g_{s}$ on both leaf surfaces was higher at the start of the measurement period in Experiment 1 than in Experiments 2 and 3. In Experiments 1 and 2, both di-1- $p$-menthene and wax reduced adaxial $g_{s}$ initially, but this effect diminished as the plants became more stressed after water was withheld and $g_{s}$ declined $(p<0.001$ for Time $\times$ Treatment interactions). There was an indication that adaxial $g_{s}$ responded similarly in Experiment 3 but this was not significant $(p=0.473$ for Time $\times$ Treatment interaction). Abaxial $g_{s}$ also responded to di-1- $p$-menthene and wax in Experiment 2 ( $p=0.005$ for Treatment) but not in Experiments 1 and 3 . 

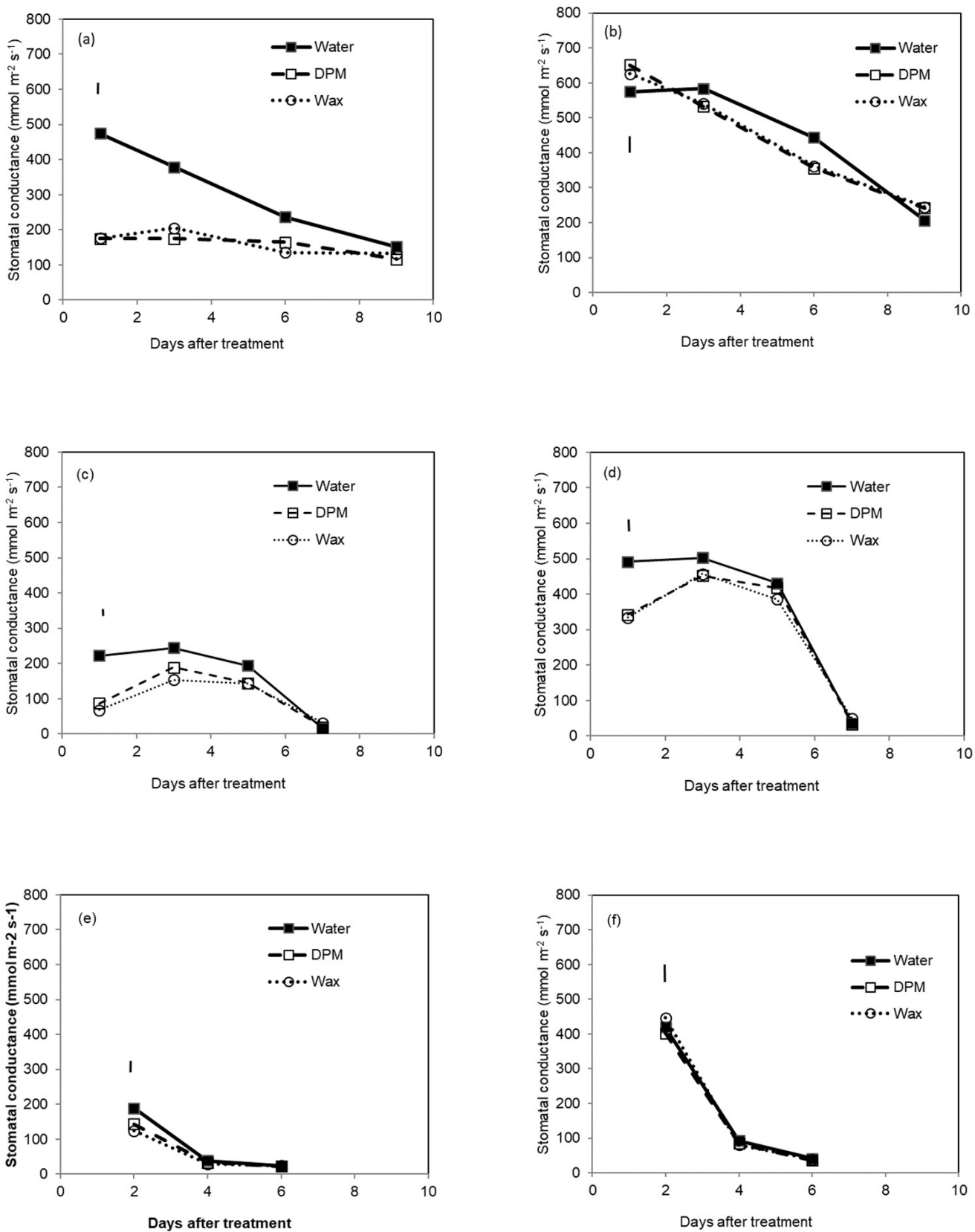

Figure 3. Adaxial $(\mathbf{a}, \mathbf{c}, \mathbf{e})$ and abaxial $(\mathbf{b}, \mathbf{d}, \mathbf{f})$ stomatal conductance of rapeseed sprayed with water (filled squares solid line), di-1-p-menthene (DPM, open squares dashed line) or wax (open circles dotted line) in Experiments $1(\mathbf{a}, \mathbf{b}), 2(\mathbf{c}, \mathbf{d})$ and $3(\mathbf{e}, \mathbf{f})$. Plants watered before treatment and then water withheld after treatment. Vertical bars are SEDs from repeated measures ANOVA. Each data point is the mean of either $18(\mathbf{a}, \mathbf{b})$ or $24(\mathbf{c}-\mathbf{f})$ readings.

Water use of control plants was greatest in Experiment 1 (Figure 4), similar to stomatal conductance, and in this experiment di-1-p-menthene gave only a small (non-significant) reduction, whereas wax significantly reduced water use by $14 \%$. Water use was not affected by either di-1- $p$-menthene or wax in Experiments 2 and 3. 


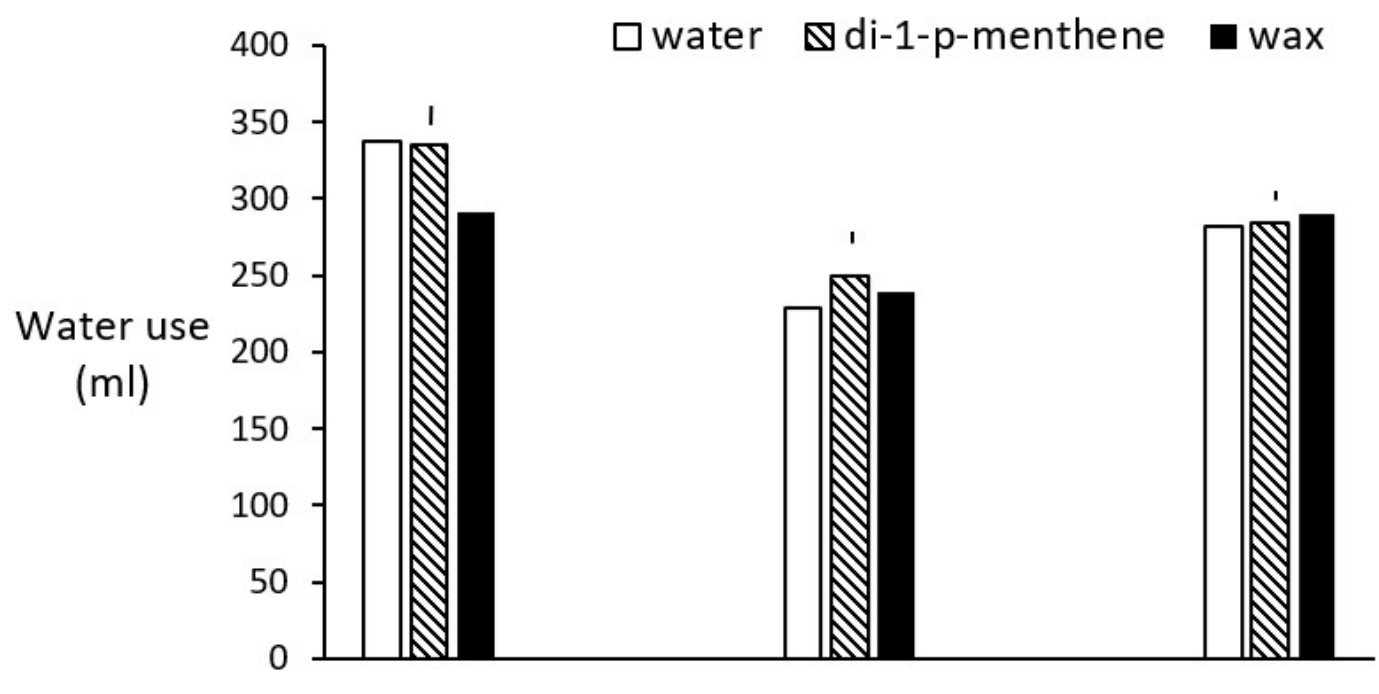

$\begin{array}{lll}\text { Exp. } 1 & \text { Exp. } 2 & \text { Exp. } 3\end{array}$

Figure 4. Comparison of sprays of water, di-1-p-menthene and wax in three rapeseed experiments on cumulative water use over 10 days after spraying. Vertical bars are SEDs.

\section{Discussion}

The composition and concentration of wax we obtained are consistent with previous work on B. Oleracea [13,14]. Laila et al. [14] give wax concentration values of $0.15 \%(\mathrm{~m} / \mathrm{m})$ on a fresh weight basis, and re-calculating our wax yield on a fresh weight basis gives a similar value of $0.18 \%(\mathrm{~m} / \mathrm{m})$.

Both low stomatal conductance at the last measurement date and cumulative water use close to the AWC indicate that the plants in all experiments were highly stressed by the end of the experiments. Higher abaxial $g_{s}$ may be because rapeseed usually has greater stomatal density on the abaxial than on the adaxial leaf surface, e.g., [15,16], as most dicotyledonous species [17]. The difference in $g_{s}$ between experiments may be because the leaves in Experiment 1 developed in higher light intensity during leaf development, which is well-known to give greater stomatal density, e.g., [17], and thus higher $g_{s}$. Leaves in Experiment 1 developed mostly in October when solar radiation was higher (monthly total $196 \mathrm{MJ} / \mathrm{m}^{2}$ ) compared with leaf development for Experiment 2 mostly in January $\left(57 \mathrm{MJ} / \mathrm{m}^{2}\right)$ and for Experiment 3 mostly in February $\left(107 \mathrm{MJ} / \mathrm{m}^{2}\right)$. In addition to the higher solar radiation for Experiment 1 indirectly giving greater $g_{s}$ through affecting stomatal density as the leaves developed, the higher solar radiation at the time of measurement would be expected to increase $g_{s}$ in Experiment 1 [18].

The differences in $g_{s}$ response between experiments may be a consequence of differences in spraying. Experiments 1 and 2 were both sprayed with hand-held sprayers until the adaxial surface was covered, and this may have delivered a greater volume, thus giving a significant reduction in $g_{s}$ compared with the automatic pot sprayer used in Experiment 3. Different operators sprayed Experiments 1 and 2, and the abaxial response in Experiment 2, but not in Experiment 1, may result from a difference in hand-spraying technique between operators. In future experiments, the spraying conditions may need further investigation since leaf coverage with antitranspirants is important for blocking stomata to reduce transpiration, and coverage varies with spray parameters, e.g., dose rate [19].

The lack of response of water use in Experiments 2 and 3 may possibly be because the water use and $g_{s}$ of control plants were lower in these experiments compared with in Experiment 1.

The experiments show that wax formulated with glycerol monostearate is generally as effective as di-1-p-menthene in reducing stomatal conductance when sprayed at $1 \%(v / v)$. 
This is a much lower concentration of active substance (a.s.) for wax since the wax before dilution was $6 \%(\mathrm{~m} / \mathrm{m})$ a.s. whereas di-1- $p$-menthene before dilution was $96 \%$ (volumetric or gravimetric not stated) a.s., possibly implying a much lower optimum concentration of wax than of di-1-p-menthene. Further experiments are needed to confirm this implied difference in activity, and, if it is confirmed, three possible reasons could be:

1. Wax may be more effective than di-1-p-menthene at blocking stomata, as shown previously for petroleum-derived wax products [20,21].

2. The glycerol monostearate used to formulate the wax for spraying may have also acted as an antitranspirant since both the alcohol and acid parts of this ester are known to have antitranspirant properties $[22,23]$.

3. Another plant component co-extracted with the wax may have had antitranspirant activity, e.g., if abscisic acid was co-extracted, as this hormone is a metabolic antitranspirant [3].

The third objective of the study was to compare the cost of the wax with the cost of di-1-p-menthene. The cost of extracting the wax is estimated at GBP $167 / \mathrm{kg}$ (equivalent to USD $225 / \mathrm{kg}$ ). This calculation assumes: a wax concentration of $1.5 \%$ in the waste biomass (similar to the concentration found in this study); a $1000 \mathrm{~kg}$ batch of wax is extracted; a currency conversion of 1.35 USD/GBP. An approximate cost of production for a formulated wax AT (based on the wax cost only) at $6 \%(\mathrm{~m} / \mathrm{m})$ as used in this research, would be GBP $10.02 / 1$ or USD $13.53 / \mathrm{L}$ ). The retail price of a biostimulant with this cost of production may possibly have to be in the region of USD 130/L to be cost effective for commercial sale (S. Adams, Plant Impact, Personal communication). In comparison, the di-1-p-menthene product (Vapor Gard) retail price per US gallon (3.79 L) is USD 69.9 [24] or a unit price of USD 18.44/L, indicating that a wax AT would need a much lower cost of production than USD 13.53/L to be a viable commercial proposition. It is possible that the cost of production of a formulated wax antitranspirant can be kept low if: a lower wax concentration can be used in the formulated antitranspirant as implied from the greater efficacy; larger batch sizes of wax can be extracted; waste biomass with greater wax concentration can be sourced; the wax can be a co-product from biomass utilization in an integrated biorefinery.

Further work is necessary to investigate: optimal spraying conditions; dose-response characteristics of the wax compared with di-1- $p$-menthene (to confirm the greater activity of the wax); activity of the formulation component glycerol monostearate applied separately; leaf photosynthesis before and after spraying; ways to lower the cost of production; performance of the wax in the field in a range of countries with different climatic conditions.

In conclusion, we have shown that leaf wax can be extracted from cauliflower leaf waste using supercritical $\mathrm{CO}_{2}$ and can be formulated as a film antitranspirant for spraying; this wax formulation had similar efficacy to a current commercial film antitranspirant (di-1- $p$-menthene) for reducing stomatal conductance and water use of young glasshouse-grown plants of rapeseed. A lower cost of production of the wax is needed for commercial exploitation.

Author Contributions: Conceptualization, P.K. and R.M.; formal Analysis, M.F., M.W. and P.K.; funding acquisition, P.K. and R.M.; investigation, G.-S.L., M.F. and M.W.; methodology, G.-S.L., M.F. and M.W.; project administration, P.K. and R.M.; resources, M.M.; supervision, P.K. and R.M.; visualization, P.K. and G.-S.L.; writing-original draft, P.K., M.F. and G.-S.L.; writing-review and editing: P.K., M.F. and M.W. All authors have read and agreed to the published version of the manuscript.

Funding: This work was supported by grant number POC15_02 of the Food Processing Waste and By-Products Utilisation Network (FoodWasteNet) of the UK Biological Sciences and Biotechnology Research Council (BBSRC).

Institutional Review Board Statement: This study was approved by The Harper Adams University Research Ethics Committee.

Informed Consent Statement: Not applicable.

Data Availability Statement: The detailed data summarised in the figures in this paper are available from the corresponding authors. 
Acknowledgments: We are grateful to Dominic Scicchitano (Miller Chemical and Fertilizer, USA) for providing Vapor Gard.

Conflicts of Interest: The authors declare no conflict of interest. The funders had no role in the design of the study; in the collection, analyses, or interpretation of data; in the writing of the manuscript, or in the decision to publish the results.

\section{References}

1. Farooq, M.; Hussain, M.; Ul-Allah, S.; Siddique, K.H.M. Physiological and agronomic approaches for improving water-use efficiency in crop plants. Agric. Water Manag. 2019, 219, 95-108. [CrossRef]

2. Jovanovic, N.; Pereira, L.S.; Paredes, P.; Pôças, I.; Cantore, V.; Todorovic, M. A review of strategies, methods and technologies to reduce non-beneficial consumptive water use on farms considering the FAO56 methods. Agric. Water Manag. 2020, $239,106267$. [CrossRef]

3. Mphande, W.; Kettlewell, P.S.; Grove, I.G.; Farrell, A.D. The potential of antitranspirants in drought management of arable crops: A review. Agric. Water Manag. 2020, 236, 106143. [CrossRef]

4. Abdullah, A.S.; Aziz, M.M.; Siddique, K.H.M.; Flower, K.C. Film antitranspirants increase yield in drought-stressed wheat plants by maintaining high grain number. Agric. Water Manag. 2015, 159, 11-18. [CrossRef]

5. Weerasinghe, M.M.; Kettlewell, P.S.; Grove, I.G.; Hare, M.C. Evidence for improved pollen viability as the mechanism for film antitranspirant mitigation of drought damage to wheat yield. Crop Pasture Sci. 2016, 67, 137-146. [CrossRef]

6. Faralli, M.; Grove, I.G.; Hare, M.C.; Kettlewell, P.S. In-field film antitranspirant application shows potential yield protection from flowering stage drought periods in winter canola Brassica napus L. Crop Pasture Sci. 2017, 68, 243-253. [CrossRef]

7. Palliotti, A.; Panara, F.; Famiani, F.; Sabbatini, P.; Howell, G.S.; Silvestroni, O.; Poni, S. Postveraison application of antitranspirant di-1-p-menthene to control sugar accumulation in Sangiovese grapevines. Am. J. Enol Vitic 2013, 64, 378-385. [CrossRef]

8. Di Vaio, C.; Marallo, N.; Di Lorenzo, R.; Pisciotta, A. Anti-transpirant effects on vine physiology, berry and wine composition of cv. Aglianico (Vitis vinifera L.) grown in South Italy. Agronomy 2019, 9, 244. [CrossRef]

9. Tassone, E.E.; Lipka, A.E.; Tomasi, P.; Lohrey, G.T.; Qian, W.; Dyer, J.M.; Gore, M.A.; Jenks, M.A. Chemical variation for leaf cuticular waxes and their levels revealed in a diverse panel of Brassica napus L. Ind. Crop. Prod. 2016, 79, 77-83. [CrossRef]

10. Xue, D.; Zhang, X.; Lu, X.; Chen, G.; Chen, Z.H. Molecular and evolutionary mechanisms of cuticular wax for plant drought tolerance. Front. Plant Sci. 2017, 8, 621. [CrossRef] [PubMed]

11. RHS John Innes potting compost. Available online: https://www.rhs.org.uk/soil-composts-mulches/john-innes-compost (accessed on 5 January 2022).

12. Saeed, H. Investigation of Partial Rootzone Drying in Potatoes Solanum tuberosum L. Ph.D. Thesis, Harper Adams University, Newport, Shropshire, UK, 2008. Available online: https:/ / ethos.bl.uk/OrderDetails.do?uin=uk.bl.ethos.492006 (accessed on 26 January 2021).

13. Baker, E.A. The influence of environment on leaf wax development in Brassica oleracea var. Gemmieera. New Phytol. 1974, 73, 955-966. [CrossRef]

14. Laila, R.; Robin, A.H.K.; Yang, K.; Park, J.; Suh, M.C.; Kim, J.; Nou, I. Developmental and genotypic variation in leaf wax content and composition, and in expression of wax biosynthetic genes in Brassica oleracea var. capitate. Front. Plant Sci. 2017, 7, 1972. [CrossRef] [PubMed]

15. Major, D.J. Stomatal frequency and distribution in rape. Can. J. Plant Sci. 1975, 55, 1077-1078. [CrossRef]

16. Faralli, M.; Grove, I.G.; Hare, M.C.; Boyle, R.D.; Williams, K.S.; Corke, F.M.; Kettlewell, P.S. Canopy application of film antitranspirants over the reproductive phase enhances yield and yield-related physiological traits of water-stressed oilseed rape (Brassica napus). Crop Pasture Sci. 2016, 67, 751-765. [CrossRef]

17. Ticha, I. Photosynthetic characteristics during ontogenesis of leaves. VII: Stomata density and sizes. Photosynthetica 1982, 16, 375-471.

18. Jones, H.G. Plants and Microclimate, 2nd ed.; Cambridge University Press: Cambridge, UK, 1992.

19. Xiang, J.; Hare, M.; Vickers, L.; Kettlewell, P.S. Estimation of film antitranspirant spray coverage on rapeseed (Brassica napus L.) leaves using titanium dioxide. Crop Prot. 2021, 142, 105531. [CrossRef]

20. Davies, W.J.; Kozlowski, T.T. Short- and long-term effects of antitranspirants on water relations and photosynthesis of woody plants. J. Am. Soc. Hortic. Sci. 1974, 99, 207-304.

21. Anderson, J.E.; Kreith, F. Effects of film-forming and silicone antitranspirants on four herbaceous plant species. Plant Soil 1978, 49, 161-173. [CrossRef]

22. Shanan, N.T.; Shalaby, E.A. Influence of some chemical compounds as antitranspirant agents on vase life of Monstera deliciosa leaves. Afr. J. Agric. Res. 2011, 6, 132-139.

23. Palis, R.K. Effect of Some Antitranspiration Chemicals on Photosynthesis and Respiration of Corn and Soybean Seedlings. Ph.D. Thesis, Kansas State University, Manhattan, KS, USA, 1970. Available online: https://krex.k-state.edu/dspace/bitstream/ handle/2097/10161/LD2668T41970P348.pdf?sequence=1 (accessed on 8 December 2020).

24. SeedRanch Millers Vapor Gard Anti-Transpirant Concentrate-1 Gallon. Available online: https://www.seedranch.com/MillersVapor-Gard-Concentrate-1-Gallon-p/vapor-gard-gallon.htm (accessed on 5 January 2022). 